\title{
Children living with Progeria
}

\begin{abstract}
Hutchinson-Gilford Progeria syndrome is a rare, progressive genetic condition characterized by the dramatic, rapid appearance of aging in childhood. Children with Progeria typically look normal at birth and during early infancy, but their growth was slow compare to other children and do not gain weight at the expected rate. It is not inherited, or passed down in families. They develop a characteristic facial appearance include growth failure, prominent eyes, aged- looking skin, a thin nose with a beaked tip, thin lips, a small chin, and protruding ears. Progeria syndrome also causes alopecia, stiff joint, and a loss of subcutaneous fat. Progeria does not disrupt intellectual development and motor skills such as sitting, standing, and walking. People with Progeria syndrome experience severe hardening of the arteries beginning in childhood and increases the chances of having a heart attack or stroke at early age. These serious complications can worsen the children and develops life-threatening.
\end{abstract}

Volume 3 Issue 4 - 2017

\author{
Akoijam Sangita Devi,' Somibala Thokchom, ${ }^{2}$ \\ Akoijam Mamata Devi ${ }^{3}$ \\ 'Associate Professor, MM Institute of Nursing, India \\ ${ }^{2}$ Nursing Tutor, Rufaida College of Nursing, India \\ ${ }^{3}$ Associate Professor, Faculty of Nursing, SGT University, India
}

Correspondence: Akoijam Sangita Devi, Associate Professor, MM Institute of Nursing, India, Tel + 199034311708 ,

Email akdevi8I@Gmail.com

Received: November 03, 2016 | Published: July 24, 2017

Keywords: progeria, aging, childhood, growth, genetic

\section{Objective}

Progeria is a rare genetic condition characterized by an accelerated aging in children. Objective of this article is to present an over view regarding the identification and management of children living with Progeria.

\section{Introduction}

Hutchinson-Gilford Progeria Syndrome "HGPS" or "Progeria" is a rare, fatal genetic condition characterized by an appearance of accelerated aging in children. ${ }^{1,2}$ Progeria is derived from Greek word and means "prematurely old". While there are different forms of Progeria, the classic type is Hutchinson-Gilford Progeria Syndrome, which was named after the doctors who first described it in England by Dr. Jonathan Hutchinson in 1886, and Dr. Hastings Gilford in 1897. It is classified as a segmental progeroid syndrome hence multiple organs and tissues reproduce phenotypes associated with normal aging. ${ }^{3,4}$

Other Progeroid syndromes include Werner's syndrome, also known as "adult Progeria" which does not have an onset until teenager, with a lifespan of 40's and 50's. ${ }^{1,5}$ The average life expectancy of children with Progeria is about age of 13 , but some are die younger and some are live 20 years or longer. ${ }^{6,7}$ The disease affects all races equally and both sexes. It affects about 1 in every 4 million births worldwide. ${ }^{1}$

A single mistake in a certain gene causes it to make an abnormal protein. When cells use this protein, called progerin, they break down more easily. Progerin builds up in many cells of child's with Progeria, causing them to grow old quickly. Progeria is not inherited, or passed down in families. ${ }^{1,5}$ When child get older, they get disease seen in adults age 50 and older such as bone loss, atherosclerosis, heart disease and stroke. Progeria affects growth and development of children but it doesn't affect intelligence. ${ }^{1}$ Children with Progeria have a remarkable similar appearance despite differing ethnic backgrounds. ${ }^{3}$ There is no cure for Progeria, but FTIs (farnesyl transferase inhibitors), is a type of cancer drug, which may help to repair the damaged cells. Some children receive treatment includes growth hormone, physical and occupational therapy and also medication to prevent heart attacks and stroke. ${ }^{1,6}$

\section{Hutchinson-gilford progeria syndrome}

\section{Synonyms}

HGPS, Hutchinson-Gilford Progeria syndrome, HutchinsonGilford Syndrome, Premature aging syndrome, Progeria, Progeria of childhood. HGPS or Progeria is an extremely rare, progressive genetic disorder that causes children rapid aging, beginning within the first two years of life. ${ }^{1}$ Children with Progeria typically appear normal at birth and in early infancy, signs and symptoms such as slow growth and hair loss begin to appear. They live to an average 13 years old. ${ }^{6,7}$

\section{Incidence}

Progeria affects approximately 1 in $4-8$ million live births. There are an approximately 200-250 children living with HGPS worldwide at any given time. ${ }^{2}$ It affects both male and female equally and all races. ${ }^{1}$ Since The Progeria Research Foundation was created in 1999, HGPS cases have been discovered children with Progeria living in over 40 different countries. ${ }^{2}$ According to the Progeria Research Foundation, however, estimated there are over 250 such children fighting this disease of which 60 are from India. ${ }^{8}$

\section{Genetic changes}

Mutations occurs in the LMNA gene cause Hutchinson-Gilford Progeria syndrome. The LMNA gene produces instructions for making lamin a protein which is an essential scaffolding or supporting component of the nuclear envelope. Mutations in the LMNA gene result in the production of an abnormal version of the lamin A protein. The alteration of protein makes the nucleus unstable and damages the nucleus, produces premature die of the cells. The cellular instability leads to the process of premature aging and cause Progeria. Many Researchers are working to find out how these changes lead to the features of Progeria syndrome. ${ }^{9,10}$

\section{Inheritance pattern}

HGPS is not usually passed down in families. The LMNA gene change is almost always a chance occurs in people with no history of the disease in their family that is extremely rare. HGPS is a sporadic autosomal dominant mutation-"sporadic" as it is a new change in 
the family, and "dominant" as only one copy of the gene needs to be changed to have the syndrome. ${ }^{11}$ The chances of having a child those Parents who never had a child with Progeria are 1 in 4-8 million. But those parents who have already had kids with Progeria, the chances of it happening again are much higher-about 2-3\%. This condition is due to "mosaicism", where a parent has the genetic mutation for Progeria in a small proportion of their cells, but does not have Progeria. Prenatal testing is available to look for the LMNA genetic change that causes HGPS. ${ }^{2,12}$

\section{Etiology and pathogenesis}

Progeria is caused by a genetic mutation, which means an individual has inherited a mutated gene from parents. The mutation occurs in the LMNA gene, which is important for producing a protein that helps maintain the structural integrity of the nucleus in cells., The cell structure is weak due to lack of strength in the nucleus which leads to rapid aging, or Progeria shown in Figure $1 .{ }^{6} \mathrm{Lamin} \mathrm{A} / \mathrm{C}$ also known as LMNA and it belongs to the lamin family of proteins that in humans is encoded by the LMNA gene. ${ }^{10}$

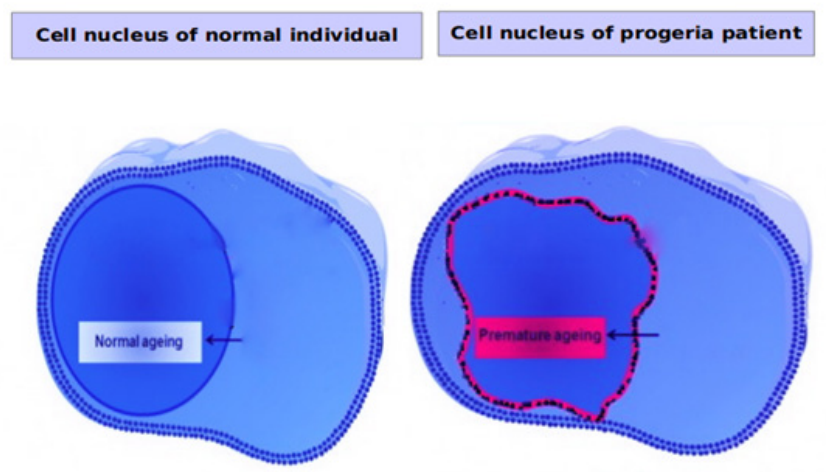

Figure I Healthy and progeria cell nucleus.

In normal cell the LMNA gene encodes a protein called prelamin A. Prelamin A protein has a sticky Farnesyl group adhere to its end, which helps it to reach the nuclear lamina and form a normal state of nucleus. In progeria cell Farnesyl remains adhere to prelamin A protein. And there is a production of progerin, an abnormal form of prelamin A. Progerin is anchored to the nuclear rim and developed premature aging as shown in Figure 2. ${ }^{11}$

\section{Progeria is a mutation in the LMNA gene}

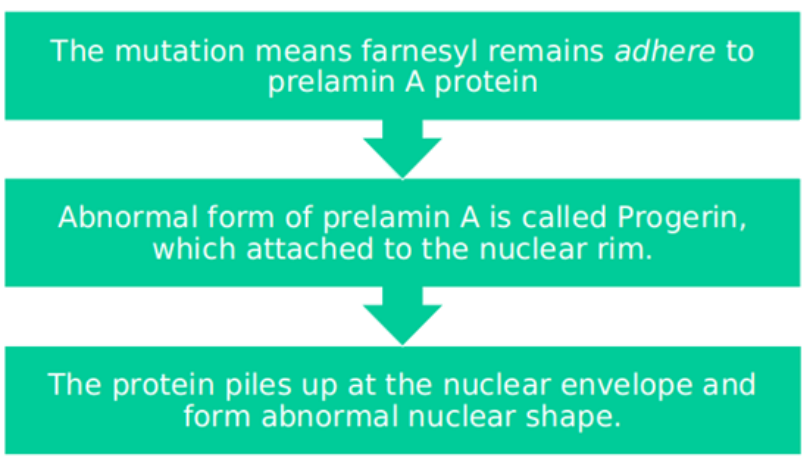

Figure 2 Pathogenesis of progeria cell.

\section{Sign and symptoms}

Most children with Progeria are usually born healthy, but they begin to show many signs and symptoms of the disease within the first 2 year of life. Child with Progeria failure of growth and development or gain weight normally They develop many physical feature including: aged-looking skin, a bigger head, large eyes, a small lower jaw, a thin nose with a "beaked" tip, ears that stick out, visible veins, slow and abnormal tooth growth, a high-pitched voice, loss of body fat and muscle, skin atrophy, hair loss including eyelashes and eyebrows, stiffness of joints as shown in Figure 3. Children have a remarkable similar appearance despite differing ethnic backgrounds. ${ }^{3}$

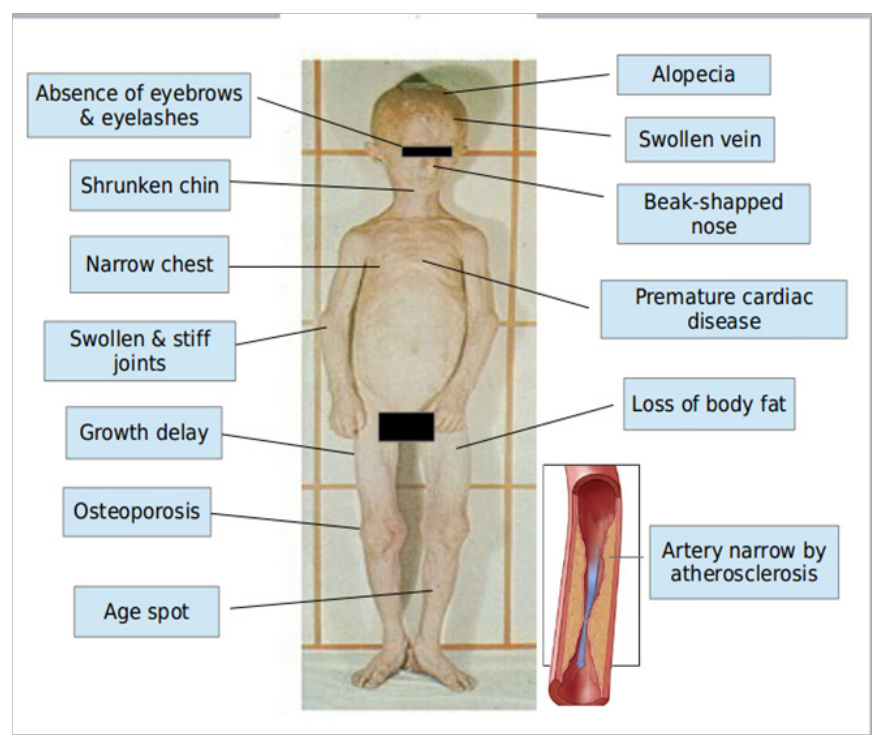

Figure 3 Sign and symptoms of progeria.

Progeria doesn't affect the intelligence or brain development. As children with Progeria get older, they get many diseases which seen in mid - adult age 50s and older, include hips dislocate, osteoporosis, generalized hardening of the arteries, and heart disease. ${ }^{1,6}$ Children with Progeria usually die of heart attacks or strokes at an average age of 14 years. ${ }^{1}$

\section{Diagnostic finding}

The pediatrician may recognize Progeria based on signs and symptoms characteristic of the syndrome during a routine checkup as symptoms of Progeria are very noticeable. Initial clinical evaluation such as child's appearance and medical records can help to point the condition. The Progeria Research Foundation has a Diagnostic Testing Program: to identify the specific genetic change, or mutation, in the Progeria gene that leads to HGPS. ${ }^{2}$ Physician will perform an audio-gram, vision acuity test to check hearing and vision. The Baby's Growth and Development chart to track the developmental milestones of the children and concerned in specialist of medical genetics (if needed). ${ }^{6} \mathrm{X}$-ray to identify the deformities and bone changes showing in Figure 4. Blood test to check for a mutation on the specific gene responsible for Progeria. ${ }^{13,14}$

\section{Treatments}

There is no cure for Progeria, at this time, but researchers are working on finding one. Treatments usually help to delay some of the 
disease's symptoms includes: FTIs (farnesyltransferase inhibitors), is a kind of cancer drug, which may repair the damaged cells. Administer a low dose of aspirin every day can help to prevent heart attacks and stroke. Coagulants and statins; anticoagulants to help prevent blood clots and statins to lower cholesterol. Growth hormone can help build height and weight of the children. ${ }^{15,16}$ Physical and occupational therapy; these therapies can help the child remain active if they have joints stiffness or hip problems. ${ }^{1,6}$

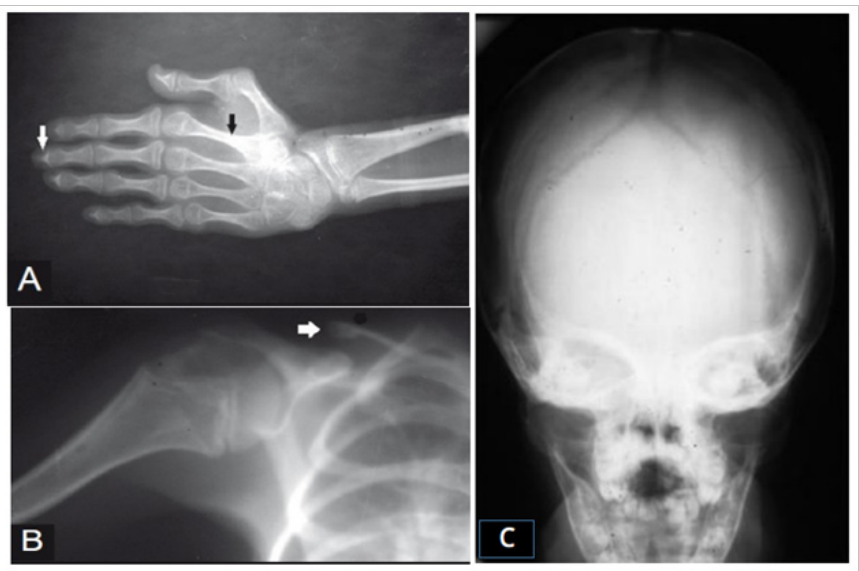

Figure 4 X-ray of $(A)$ hand showing terminal phalanges (white arrow) and osteoporotic changes (black arrow). (B) Shoulder joint showing dystrophic and short clavicle (white arrow). (C) Mandible and facial bones are hypoplastic, skull is large and poorly ossified.

\section{Surgery}

Some children with Progeria may have CABG (Coronary Artery Bypass Grafting) surgery or Angioplasty to slow the progression of heart disease.

\section{Care at home}

Make sure children with Progeria stays well-hydrated; children are more probably to get dehydrated. So, they need to drink plenty of water, especially during an illness or in hot weather. Provide small, frequent meals; growth and nutrition can be an issue for children with Progeria, giving small meals more often can help to increase calorie intake. Provide regular physical activity; consult with paediatrician or physiotherapist to learn which activities are best for the child. Cushioned shoes or shoe inserts; get cushioned shoes can ease discomfort and encourage the child to play and stay active. ${ }^{1}$ Use a broad-spectrum sunscreen with at least SPF 15 can help to protect from skin damage. Apply sunscreen for every two hours or more often if child is swimming or perspiring. Child should be up to date on childhood immunizations; children with progeria are not at increased risk of infection, but there is at risk if exposed to infectious diseases like all children. Provide opportunity of learning for children with Progeria. Progeria won't affect mental development of the child; in fact, intelligence tends to be average to above average, so he or she can attend school at an age-appropriate level. ${ }^{16}$

\section{Prognosis}

As there is no known cure, the average lifespan for Progeria is 13 years, although some live into their $20 \mathrm{~s}^{6,15}$ At least $90 \%$ of children with Progeria die from complications such as heart attack or stroke., ${ }^{2,16}$ Progeria does not affect mental development but intelligence tends to be average or above average. ${ }^{16,17}$ With respect to the features of aging, the development of symptoms is comparable to aging at a rate eight to ten times faster than normal. They do not show neurodegeneration or cancer predisposition. Progeria does not develop the so-called "wear and tear" conditions commonly related with aging, such as cataracts and osteoarthritis. ${ }^{18}$ Sufferers of Progeria have normal reproductive development. ${ }^{19}$

\section{Case study I}

A 14-year-old girl child presented with progressive history of skin folding, failure to thrive and inability to squat for the past three to four years. The child had also developed loss of hair for the past few years. The girl was normal till one year of age when the parents started noticing the above features. The child had normal intelligence and they had no family history of similar complaints. Physical examination revealed that short stature, undernourished, prominent eyes, multiple rough patches and thickened skin, especially over the dorsum of the hands and shoulders. The fingers appeared broad and stubby at the ends. The girl was provisional diagnose as Progeria based on the history and clinical findings.

Blood investigations were normal except for increased serum cholesterol and increased urinary excretion of hyaluronic acid. The child was subjected to a skeletal survey to confirm the diagnosis. Radiographs of the skull showed diastasis of the sagittal suture with numerous wormian bones. The mandible showed the hypoplastic with infantile angle and the chest showed sloping ribbon-like ribs with thinning of both third ribs posterior. The lateral half of both the clavicles was absent. The dorsal spine in the lateral projection showed presence of fish mouth vertebrae. The hands and feet revealed resorption of terminal phalanges. The above radiological findings confirmed the clinical diagnosis of Progeria. ${ }^{20}$

\section{Case study 2}

Anjali Kumari seven year old and her brother Keshav Kumar 18 month old from Ranchi, Jharkhand India, have been suffering from a rare fatal genetic condition, giving them a rapid appearance of aging in childhood. Born to father name Shatrughan Rajak and mother Rinki Devi, they also have an older sister Shilpi, 11 years, who do not have the disease.

Anjali experiences ailments usually suffered by old age such as sagging skin, breathing difficulties, poor eyesight, stiff and painful joint, swollen faces, and low immunity. And due to her low immunity she picks up illnesses quickly. A paediatrician from a government hospital of Ranchi investigates the siblings and said: They suffer from a rare form of Progeria and also a disease called Cutis Laxa. Anjali hopes one day she and brother will be able to look normal. Their father Shatrughan can only expenses for homeopathic medicines, which is not helping his kids anyway. ${ }^{21}$

\section{Conclusion}

HGPS or "Progeria" is a rare, fatal genetic condition characterized by rapid appearance of accelerated aging in childhood. They look normal at birth, but delay growth and development compare to normal children. Progeria is caused by a genetic mutation occurs in the LMNA gene, which helps to produce a protein to maintain structural integrity. The cell structure is weak without strength in the nucleus and leads to rapid aging or Progeria. As child gets older, they get disease seen in people age 50 and older such as bone loss, atherosclerosis and heart disease. It doesn't affect intelligence or brain development. There is 
no cure for Progeria, but FTIs may repair the damaged cells. Some children receive treatment includes growth hormone, medication to prevent heart attacks and stroke, and physical and occupational therapy.

\section{Acknowledgements}

With profound gratitude I express my heartfelt veneration toward my esteemed; invaluable friends and family members for enlightening guidance, interest, valuable suggestions and consistent encouragement at all stages of work. I deeply appreciate their untiring and outstanding contribution, encouraging words for construction of view successfully.

\section{Conflicts of interest}

The author declares no conflict of interest.

\section{References}

1. WebMD medical reference. Reviewed by Amita Shroff MD. 2016.

2. Progeria research foundation.

3. Eriksson M, Brown WT, Gordon LB, et.al. Recurrent de novo point mutations in lamin A cause Hutchinson-Gilford progeria syndrome. Nature. 2003;423(6937):293-298.

4. Gene Review: Hutchinson - Gilford progeria syndrome.

5. Halaschek-Wiener J, Brooks-Wilson A. Progeria of stem cells: stem cell exhaustion in Hutchinson-Gilford Progeria syndrome. J Gerontol A Biol Sci Med Sci. 2007;62(1):3-8.

6. Amber Erickson Gabbey, George Krucik. Progeria Syndrome: Health line; 2013.

7. Gonzalez JM, Pla D, Perez-Sala D, et al. A-type lamins and HutchinsonGilford progeria syndrome: pathogenesis and therapy. Front Biosci. (Schol Ed). 2011;3:1133-1146.
8. The Indian Express. May 4, 2016. Mumbai: Nihal Bitla, who became face of Progeria campaign in India, dies at 15.

9. Ghosh S, Zhou Z. Genetics of aging, Progeria and lamin disorders. Curr Opin Genet Dev. 2014;26:41-46.

10. De Sandre-Giovannoli A, Bernard R, Cau P, et al. Lamin a truncation in Hutchinson-Gilford progeria. Science. 2003;300(5628):2055.

11. Cao K, Collins FS. Rapamycin reverses cellular phenotypes and enhances mutant protein clearance in hutchinson-gilford progeria syndrome cells. Science Translational Medicine. 2011;3(89):89ra58.

12. Halaschek Wiener J, Brooks-Wilson A. Progeria of stem cells: stem cell exhaustion in Hutchinson-Gilford Progeria syndrome. J Gerontol A Biol Sci Med Sci. 2007;62(1):3-8.

13. Genetic testing registry: Hutchinson - Gilford syndrome.

14. Hennekam RC. Hutchinson-Gilford Progeria syndrome: review of the phenotype. Am J Med Genet A. 2006;140(23):2603-2624.

15. Steve Sternberg. Gene found for rapid aging disease in children. USA; 2003.

16. Progeria.

17. Brown WT. Progeria: a human-disease model of accelerated aging. Am J Clin Nutr. 1992;55(6 Suppl):1222S-1224S.

18. Learning About Progeria.

19. R Corcoy, A Aris, A De Leiva. Fertility in a Case of Progeria. Am J Med Sci. 1989;297(6):383-384.

20. Rajul Rastogi, SM Chander Mohan. Progeria syndrome: a case report. Indian J Orthop. 2008;42(1):97-99.

21. The logical Indian. April 15, 2016. Ranchi: 18 Months and 7 Yrs old kid suffers with a rare condition which makes them Look decades older. 